\title{
Aportes para la construcción de un archivo indígena local: la Encuesta Nacional de Folklore en la provincia de San Luis, Argentina, 1921
}

\section{Resumen}

En el presente trabajo analizamos un material folklórico recopilado en la provincia de San Luis en 1921, a partir de una encuesta nacional encomendada por el Consejo Nacional de Educación. Para ello, presentamos los documentos en su contexto intelectual y estatal-nacional particular a fin de mostrar que las referencias a pueblos indígenas eran parte del ámbito de indagación folklórica. Por medio de un estudio pormenorizado de los legajos existentes en esta provincia nos proponemos analizar en qué medida este material puede aportar a la comprensión de la circulación de memorias, prácticas y adscripciones indígenas, luego de concretada la llamada "Conquista del Desierto", con el fin de construir un archivo indígena local.

Contribution to the construction of a local indigenous archive: National Survey on Folkloric material in San Luis province, Argentina, 1921

\begin{abstract}
The current paper analyzes folkloric material gathered during a national survey in San Luis province -Argentina- in 1921, conducted by the Consejo Nacional de Educación (National Council of Education). First, we present the collected documents in their intellectual and state administration context, in order to show how the references to indigenous people are part of the folkloric
\end{abstract}

Palabras clave

folklore

pueblos indígenas San Luis, Argentina archivo

Key words

folklore

Indigenous peoples San Luis, Argentina archive 
1. Reflexión de la maestra Teresa C. de Pérez de la escuela 148 ubicada en El Arenal -Departamento Coronel Pringles, San Luis-, en el legajo que da cuenta de su participación en la encuesta nacional de folklore (INAPL, ENF Leg. 111, f. 8).
2. Cabe aclarar que si bien en el contexto se enunciaba la tarea como una "recopilación" de datos, aquí entendemos que todos los registros presentes en los legajos son producciones dialógicas entre el informante y el maestro.

3. Podemos decir que el material se ubica en un lugar "intermedio entre el documento escrito y el testimonio etnográfico" (Farberman, 2014: 2).

4. Además podemos mencionar algunas investigaciones que han abordado de distinto modo el análisis de este material folklórico. Sobre las características de la ENF y su contexto intelectual particular, ver Dupey (1998), Espósito y Di Croce (2013) y Fernández Latour de Botas (1981). Para un análisis particular del material de la ENF en la localidad de Amaicha del Valle y las tensiones clasificatorias en torno a lo criollo e indígena, ver Steiman (2011). Por su parte, De la Fuente (2007) indaga en las representaciones populares que circulaban de modo oral en el siglo XIX con respecto a los caudillos federales en La Rioja a partir del material folklórico de la encuesta. También podemos rescatar los trabajos de Diego Escolar (2007 y 2014), quien incorpora parte del corpus documental de la provincia de San Juan para el análisis de la etnogénesis huarpe. Con respecto a la provincia de San Luis, contamos con un antecedente que presenta una descripción general de la encuesta como un homenaje a los maestros participantes (Pérez Gutiérrez de Sánchez Vacca, 2002). scope. Then, through a thorough study of the files existing in this Province, and aiming to create a local indigenous archive, we analyze how this material may contribute to understand the flow of indigenous memories, practices and identifications, after the ending of the so-called Desert Campaigns.

\section{Introducción}

Se conservan aún varias palabras indígenas que los años no han podido evitar. Siempre me pregunto: ¿por qué razón se trata hoy en la escuela moderna de acostumbrar al niño que no use esas palabras? ¿Acaso no nos sentimos orgullosos de tener en nuestras venas, un pigmento de sangre indígena? ¿Por qué sus obras manuales son tan apreciadas y no sus vocales? ${ }^{1}$

Tomamos esta cita como punto de partida porque sintetiza varias de las preocupaciones que abordaremos en este trabajo. Estas palabras fueron escritas por una maestra en el marco de una Encuesta Nacional de Folklore (ENF, en adelante) que se realizó en Argentina en 1921 con el objetivo de recopilar la literatura popular "dispersa" en las regiones del interior. Había un proyecto explícito de recuperación y preservación de tradiciones, saberes y prácticas autóctonas en el interior del país. Se creía que allí estas habían permanecido "puras", al tener menor contacto con la inmigración europea que había llegado a principio del siglo XX. Este proyecto a nivel nacional se sostuvo y se llevó a cabo por medio de la institucionalidad del sistema educativo, que había adquirido un fuerte carácter nacional por medio de ciertas políticas específicas como la creación de escuelas nacionales por medio de la llamada "ley Láinez". Los maestros y maestras fueron los encargados de realizar la tarea de recopilación. ${ }^{2}$

Los maestros recibieron instrucciones sobre cómo realizar esta tarea que indicaban, por ejemplo, la necesidad de precisar el informante de la narración, su edad y ciertos criterios de clasificación de la información. Luego, sus producciones escritas en puño y letra eran enviadas al Consejo Nacional de Educación (CNE). Más allá de las instrucciones precisas, las transcripciones se convirtieron, en muchos casos, en una suerte de cuadernos en donde volcar notas de trabajo de campo, tal como demuestra la cita del comienzo. En ese sentido, los maestros/etnógrafos pusieron por escrito una serie de saberes en circulación oral. ${ }^{3}$

El material documental se encuentra actualmente para su consulta en el Instituto Nacional de Antropología y Pensamiento Latinoamericano (INAPL) e incluye una gran diversidad de registros en torno a saberes, prácticas y discursos populares. En el presente trabajo nos proponemos analizar en qué medida este material puede aportar a la comprensión de la circulación de memorias, prácticas y adscripciones indígenas, luego de concretadas las llamadas campañas al desierto en la provincia de San Luis, con el fin de construir un archivo indígena local.

Entre otros antecedentes, ${ }^{4}$ cabe destacar la investigación de Oscar Chamosa (2008) sobre el carácter de este material folklórico en el Valle Calchaquí. Allí índica que los maestros cumplieron un rol protagónico en la des-indianización de los pobladores rurales locales al clasificarlos como "criollos". Si bien reconocían la descendencia indígena de la población del lugar, y de su cultura, evitaron identificarlos explícitamente bajo la categoría de indígena en los registros en pos de acentuar el sentido de homogeneidad nacional. Por otro lado, en San Luis también operaba el arquetipo de la figura criolla ligada a 
la descendencia española aunque, tal como veremos a continuación, existen numerosos legajos de la ENF que refieren explícitamente a memorias, prácticas y adscripciones descriptas como indígenas en distintos sitios del territorio provincial -descripción que no alcanzaba de igual manera a los informantes, sobre los cuales hay escasas referencias. Aquí argumentaremos que, en este caso, estas referencias indígenas se encontraban habilitadas en tanto expresaban vestigios del pasado contenidos como en una suerte de cápsulas cerradas, que no amenazaban la uniformidad cultural local homologada a la nacional ya -aparentemente- alcanzada por parte del poblador rural criollo.

Ahora bien, si interrogamos este material desde un contexto actual que cuestiona la supuesta desaparición de los indígenas locales y tensiona las representaciones unívocas de la identidad provincial, ${ }^{5}$ creemos que la ENF resulta un acervo importante para atender a la circulación de saberes y tradiciones indígenas que habían quedado por fuera del régimen de visibilidad local una vez concretadas las llamadas campañas al desierto (1878-1879). En esa línea, este material puede aportar a la construcción de un archivo indígena local, entendido como un "conjunto de textos o soportes discursivos (escritos, orales, rituales, performáticos) que pueden ser articulados entre sí por las referencias que de ellos es posible sustraer sobre un tema o para iluminar un campo temático específico de conocimiento" (Escolar, 2014: 4). Es decir, así como Escolar plantea esta idea con respecto a la configuración de un archivo huarpe, aquí entendemos que este material folklórico, junto a otros que se encuentran dispersos en diversos soportes y textos, pueden resultar un aporte para analizar la circulación de prácticas y representaciones indígenas en el territorio provincial.

En términos más específicos, en el primer apartado presentaremos brevemente algunas consideraciones sobre el contexto histórico particular de la consolidación de los límites territoriales de San Luis como provincia, luego de las llamadas campañas al desierto. En el segundo abordaremos el contexto intelectual del momento de realización de la ENF, que emparentaba la tarea folklórica a ciertos principios nacionalistas. En el tercero, daremos cuenta del sistema educativo nacional que le dio factibilidad a la concreción de la ENF y el despliegue de las escuelas nacionales en la provincia de San Luis. En el cuarto apartado presentaremos un análisis de los legajos correspondientes a esta provincia, apuntando específicamente a iluminar el modo en que aparecen las referencias indígenas en los escritos enviados por los maestros.

\section{Algunas consideraciones históricas de San Luis y el espacio fronterizo}

Si bien San Luis en tanto unidad político-administrativa provincial se formó en 1820, no fue hasta las campañas militares de 1878 y 1879 de conquista del territorio indígena que estableció los límites provinciales tal como los conocemos hoy. ${ }^{6}$ Antes de que se consolide esta configuración territorial, la provincia de San Luis -y toda la república naciente- se encontraba atravesada por una "línea de frontera" ${ }^{7}$-ubicada para el año 1869 en el río Quinto- que separaba su territorio del llamado "desierto" o "tierra adentro". Allí vivían distintos pueblos indígenas con autonomía, como eran los ranqueles de la zona de la pampa central. ${ }^{8}$ En ese sentido, durante el siglo XIX gran parte de las preocupaciones de las elites dirigentes encargadas de la organización política de San Luis estaba ligada a la "situación fronteriza".
5. Actualmente, estamos frente a un proceso a nivel local que cuestiona los discursos de desaparición de los indígenas a partir de la emergencia de familias que se identifican y manifiestan indígenas y/o descendientes. Esto se tradujo en un conjunto de políticas públicas que reconocen derechos específicos, otorgando visibilidad inédita a estas poblaciones en el marco provincial.
6. El Mapa 1 muestra los límites provinciales y departamentales tal como existieron hasta 1948, momento en que se creó un nuevo departamento llamado Vicente Dupuy en lo que era el sur de las jurisdicciones La Capital y Pedernera.

7. Aunque desde la geopolítica militar esta frontera se representaba como una línea, su configuración social, cultural, política, económica y territorial era mucho más dinámica y porosa; es decir, constituía un espacio fronterizo.

8. Los ranqueles -o rankülche, gente del carrizal- residían en un área conocida como Mamüll Mapu -País del Monte- caracterizada por la presencia de bosques de caldén y ubicada en el territorio de la pampa central. Actualmente constituye el norte de la provincia de La Pampa, sur de San Luis y Córdoba. En esa zona asentaban sus tolderías, durante la segunda mitad de siglo XIX las principales fueron las ubicadas en Leubucó y Poitague y sus caciques más representativos Mariano Rosas y Baigorrita. 
9. Cabe aclarar que hacer un repaso por la historia indígena local implicaría considerar otros procesos fundamentales, como el sometimiento de los pueblos huarpes y comechingones en el marco de la conquista española temprana. Aquí nos hemos circunscripto a presentar sólo el escenario de segunda mitad de siglo XIX porque, tal como veremos más adelante, las referencias indígenas de la ENF remiten mayormente a este contexto protagonizado por "ranqueles" $\mathrm{y} / \mathrm{o}$ "araucanos" -tal como figuran en los registros.
Así como era posible identificar dos tolderías principales ubicadas en Leuvucó y Poitague al norte del territorio pampeano, los indígenas tenían una amplia capacidad de circulación e interrelación en el marco de un espacio fronterizo diverso, poroso y permeable que tenía a la localidad de Villa Mercedes -San Luis- como uno de sus puntos de interacción principal. Esto supuso un vínculo cotidiano entre "indios" y "cristianos" de diversa índole, intercalando momentos de paz con otros de mayor tensión. Finalmente, la balanza fue inclinada en favor de las fuerzas militares-estatales y el territorio indígena fue conquistado.

Distintas investigaciones han demostrado que los ranqueles sobrevivientes a las campañas militares -conceptualizadas por numerosa producción académica como genocidio (Lenton, 2011) - fueron dispersados en distintos puntos del territorio nacional tras ser tomados prisioneros. Muchos de ellos sufrieron trasladados forzosos a los ingenios azucareros de Tucumán en tanto fuerza de trabajo y otros reingresaron al Territorio Nacional de La Pampa fundado en 1884, lo que implicó el proceso de incorporación subordinada al mercado de trabajo en algunos casos y el acceso a una tenencia precaria de la tierra en la Colonia Pastoril Emilio Mitre, en otros (Lazzari, 2010; Salomón Tarquini, 2010). Si bien estas trayectorias han sido reconstruidas por la producción académica existente, aún son escasos los datos sobre cómo fue la incorporación al mercado de trabajo de aquellos ranqueles que permanecieron en el actual territorio de la provincia de San Luis y en qué puntos específicos se asentaron.

Además, cabe mencionar que este proceso de conquista efectiva estuvo acompañado por ciertos discursos de desaparición consolidados a fines de siglo XIX que "decretaron" el fin de la presencia indígena ranquel en el territorio provincial con la concreción de la "conquista del desierto". El arquetipo de la familia puntana era eminentemente criolla. Las elites dirigentes a cargo del poder político local, en alianza con Julio A. Roca, celebraban los éxitos obtenidos en las campañas militares y anunciaban que, con la muerte del cacique principal Baigorrita, se habría producido la "desaparición de la raza ranquelina". Esos discursos construyeron un escenario lineal y simplificado que omitió las complejidades inherentes a los múltiples mestizajes y contactos interétnicos propios del espacio fronterizo (Vacca, 2015). No nos explayaremos aquí en las características que adoptó el proceso de incorporación de los territorios indígenas porque excede a los objetivos de este trabajo. Pero sí entendemos fundamental presentar brevemente este pasado histórico-social para contextualizar las referencias indígenas presentes en la ENF dentro del límite provincial, lo cual analizaremos más adelante. ${ }^{9}$

\section{La encuesta, su contexto intelectual y fundamentación}

La ENF de 1921 fue una iniciativa de Juan P. Ramos, quien era vocal del CNE por entonces dirigido por Ángel Gallardo. Este Consejo era la institución principal que regulaba el sistema educativo nacional, punto en el cual profundizaremos en el apartado siguiente. El proyecto inicial de Ramos fue presentado el 1 de marzo de 1921 y sólo quince días más tarde fue dictada la resolución que aprobaba la realización de la ENF de acuerdo a las pautas delineadas en el proyecto. El artículo 1 estipulaba:

Recoger por medio de las escuelas de la ley Láinez todo el material disperso de folklore, de poesía y de música, a cuyo fin cada maestro transcribirá lo más fielmente posible todo aquello que pueda referirse a los siguientes enunciados: $1^{\circ}$ Tradiciones populares marcadamente antiguas, de cualquier carácter que 
sean [...] $2^{\circ}$ Poesías populares marcadamente antiguas, de cualquier carácter que sean (Monitor de la Educación Común, 1921a: 17).

Para justificar la realización de la Encuesta, Ramos ensalzaba la tarea científica realizada mayormente por las naciones europeas con respecto al estudio del folklore y la poesía popular. ${ }^{10}$ A diferencia de ello, consideraba que en nuestro país poco se había hecho por "desentrañar y esclarecer, a la luz de la ciencia, las tradiciones populares y poéticas de una colectividad determinada". Caracterizaba al romancero español como la fuente más rica de poesía popular; por ende, por "nuestra tradición de raza", Ramos suponía la existencia de un gran acervo en Argentina en función a esa herencia hispana. Por lo tanto, propuso la búsqueda de material "ante todo antiguo, de nuestra misma lengua o también de lenguas indígenas", ${ }^{11}$ dejando afuera todo aquello que resulte exótico, como ser las poesías populares "trasplantadas" por la inmigración europea reciente. Estos dos puntos se conjugaban sin conflicto ya que el romancero español no era interpretado como elemento exótico sino que "después de tres siglos de existencia en la memoria popular, [había] adquirido entre nosotros derecho a ser considerado como nacional" (Ramos, en Monitor de la Educación Común, 1921a: 17).

Este punto da cuenta de un contexto particular en el cual folklore y nacionalismo se retroalimentaban en la búsqueda del "alma del pueblo", frente a la llegada de inmigración y elementos culturales foráneos. ${ }^{12}$ Las clases dirigentes y las elites culturales estaban preocupadas por la consolidación de un orden social y político puesto en cuestión por la conflictividad social y heterogeneidad cultural ligada a la inmigración. Tal como lo expresaba Ramos, "el avance del cosmopolitismo" estaba poniendo en riesgo la pervivencia de ese espíritu popular que habitaba mayormente en el interior gracias al menor contacto con los inmigrantes (1921: 15). Este entramado intelectual y político legitimó la realización de la Encuesta al concebir al folklore como el instrumento que permitía "recuperar el amor a las tradiciones sustentadas en los valores ancestrales, que cohesionan al pueblo" (Blache, 1992: 75).

Ahora bien, ¿qué elementos estaban contenidos en el alma del pueblo? Mediante un proceso de selección, este discurso nacional -influenciada por Ricardo Rojas, entre otros- dejaba afuera los elementos propios de la inmigración europea reciente, tal como mencionamos, y contemplaba las tradiciones hispánicas de larga duración y las indígenas que conformaban el sustrato de la conciencia nacional. ${ }^{13}$ Aunque, tal como señala Ingrid de Jong (2005), al interior del "folklore argentino" operaba un nuevo proceso de selección jerárquico en el cual el gaucho -ligado a la raíz hispana- era ubicado como el arquetipo de la nación. En esa operación, los indígenas eran conceptualizados como expresiones "primitivas" del pasado que estaban destinadas a desparecer y que, en algunos aspectos, habían sido meros receptores de la cultura española. Por el contrario, desde esta posición, el arquetipo criollo ligado a la raíz europea no había sido permeado por los modos de ser, hacer y conocer propios de los indígenas.

En la provincia de San Luis, también encontramos una reivindicación de la figura del criollo por parte de las elites culturales ligadas al poder político local al finalizar el siglo XIX. Más específicamente, se instituye un discurso en torno a la identidad puntana encarnada por familias eminentemente criollas que expresaban un "mestizaje fundacional", entre el hombre español y la mujer indígena en el momento de la conquista española (Vacca, 2014). Así, se buscaba distinguir la configuración política y cultural encarnada en el Estado
10. La palabra "folclor" es un neologismo que significa "el saber de la gente" y fue acuñado por William Thoms en 1846. Las recopilaciones y clasificaciones de las tradiciones orales populares eran un aspecto fundamental de esta disciplina, como lo documentan los cuentos recolectados a fines de siglo XIX y principios del XX en Europa -especialmente analizados por Robert Darnton (1987). Gran cantidad de investigaciones han incorporado material folklórico como fuente de análisis, estableciendo un diálogo entre antropología e historia. Por ejemplo, el interés de E. P Thompson (1989) por conocer las costumbres populares lo alejó de una perspectiva de historia económica que explica grandes procesos y lo aproximó a la antropología social; las compilaciones de folklore fueron una gran puerta de entrada para conocer los rituales populares a los que no había podido acceder de otra manera.

11. Énfasis original.

12. En esa línea, las instrucciones a los maestros diseñadas por el CNE para la realización de la encuesta comienzan planteando una definición de folklore como "lo que sabe el pueblo" (Monitor de la Educación Común, 1921b: 3).

13. Para profundizar en las distintas posturas en torno a este tema sostenidas por las elites culturales del momento, ver Chicote (2013). 
14. Esto estuvo inicialmente regulado por la ley 463 sancionada en 1871 , luego en 1890 se sancionó la ley 2737 que establecía nuevas obligaciones a las provincias para recibir las subvenciones -como la creación de un Consejo Escolar Provincial, la Inspección Escolar y la figura de un Inspector nacional por provincia (Dubini y Orovitz, 2007). provincial y anclarla en el pasado colonial, para que permitiera diferenciar a las familias puntanas de los indígenas contemporáneos que habitaban más allá de la frontera. Este criollo expresaba una síntesis en la cual el componente indígena originario quedaba diluido por su propio destino de desaparición. Esta figura, "impura" en sus orígenes se purificó con el paso del tiempo, se solidificó hasta esencializarse y se convirtió en el arquetipo de la identidad local. En ese sentido, se refleja la operatoria recientemente señalada con respecto al folklore argentino: tal como veremos a lo largo del trabajo, en San Luis la ENF relevaría el "saber del pueblo" criollo, ligado a la raíz hispana, y sería claramente diferenciable de aquellas tradiciones y saberes indígenas que podrían haber permanecido como una suerte de cápsula cerrada.

Al tener en cuenta la relación de retroalimentación entre folklore y nacionalismo, entendemos por qué el CNE estipuló que los maestros incluyeran en el relevamiento referencias indígenas. Tomando como antecedente modos de clasificación ya difundidos en estudios folklóricos de otros países, Juan P. Ramos y Pablo A. Córdoba prepararon las instrucciones que fueron enviadas a los maestros adaptando estos modos al "folklore argentino", tarea que se vehiculizó mediante la previa expansión del sistema educativo nacional en todas las provincias y territorios nacionales.

\section{Caracterización de las escuelas Láinez en San Luis y su participación en la encuesta}

Las primeras décadas del siglo XX presentaban un escenario favorable para la ampliación de la educación primaria en la Argentina. En esa línea, identificamos dos mojones legales principales y un actor clave, como eran los maestros y maestras para la viabilidad institucional de la ENF a nivel nacional. En primer lugar, cabe mencionar la ley 1420 sancionada en el 8 de julio de 1884, la cual fue el puntapié principal que permitió extender la educación común y conformar un sistema nacional educativo. Tal como sostiene Donoso Romo (2009), esta legislación se plasmó en un escenario que implicaba un cambio de época -compartido por otros países de América Latina-, en el cual comenzó a considerarse importante que los sectores populares accedan a la instrucción básica. La fundamentación de esta nueva percepción incluía argumentos ilustrados y civilizatorios en torno a la construcción de la nación por parte de los sectores dirigentes así como razones de otra índole, como la necesidad de contar con trabajadores instruidos frente a la urbanización e industrialización y de contener las crisis sociales ligadas a la participación política de los sectores populares.

En segundo lugar destacamos la ley 4874 sancionada el 30 de septiembre de 1905 por iniciativa del senador Manuel Láinez, la cual estipulaba que el CNE procedería a instalar escuelas "elementales, infantiles, mixtas y rurales" en las provincias que así lo solicitasen, teniendo en consideración las tasas de analfabetismo para determinar su ubicación. Hasta el momento, la obligación de impartir educación estaba mayormente circunscripta a las provincias mediante lo estipulado en el artículo 5 de la Constitución Nacional y el gobierno central intervenía mediante la entrega de subvenciones escolares. ${ }^{14}$ Sin embargo, la sanción de la ley Láinez da cuenta de un proceso creciente de nacionalización de la educación primaria, en donde el Poder Ejecutivo nacional tenía potestad de injerencia "directa" creando y regulando las nuevas escuelas. Rápidamente se vieron los efectos de la ley y se difundieron las escuelas nacionales en las provincias. En el caso de San Luis, hasta 1906 existían 40 escuelas nacionales, 
115 provinciales anexas y 4 particulares; mientras que para 1936 las nacionales ascendieron a 283 y las provinciales a 128 (Arata y Ayuso, 2007: Cuadros 1 y 2).

Por consiguiente, las dos leyes descriptas son parte de un proceso, en marcha, de configuración de un sistema nacional de educación que incluía resortes institucionales específicos. En 1884 se crea el CNE, cuyos cuatro miembros eran enteramente nombrados por el Poder Ejecutivo sin participación de otros organismos, como el Congreso. De este modo, se fortaleció el rol del poder central en la regulación de la instrucción básica. ${ }^{15}$ Este entramado legal e institucional que sostuvo la estructura de la educación primaria es fundamental para comprender el alcance de la ENF en San Luis.

Tal como indica el Cuadro 1, la presencia de escuelas nacionales creadas a partir de la ley Láinez era relativamente pareja entre los distintos departamentos existentes en la provincia, así como aquellas que fueron parte de la ENF. De la totalidad de las escuelas, 134 enviaron uno o más legajos al CNE, lo cual implicó la participación de 176 maestros. ${ }^{16}$ El mayor índice de participación lo encontramos en el Departamento Pedernera, sitio en el cual existen 43 legajos distintos. A su vez, en esta jurisdicción es donde encontramos la mayor cantidad de referencias indígenas -tal como analizaremos en el próximo apartado.

\begin{tabular}{|l|c|c|c|c|}
\hline \multicolumn{1}{|c|}{$\begin{array}{c}\text { Departamentos } \\
\text { (San Luis) }\end{array}$} & Población* & $\begin{array}{c}\text { Escuelas Láinez } \\
\text { existentes** }\end{array}$ & $\begin{array}{c}\text { Escuelas Láinez } \\
\text { participantes de } \\
\text { la ENF*** }\end{array}$ & $\begin{array}{c}\text { Maestros } \\
\text { participantes de la } \\
\text { ENF*** }\end{array}$ \\
\hline La Capital & 24108 & 36 & 17 & 18 \\
\hline Coronel Pringles & 8302 & 34 & 17 & 17 \\
\hline Pedernera & 34492 & 35 & 19 & 43 \\
\hline San Martín & 9334 & 44 & 20 & 21 \\
\hline Junín & 10605 & 34 & 20 & 15 \\
\hline Ayacucho & 12042 & 43 & 13 & 11 \\
\hline Belgrano & 6920 & 26 & 10 & 8 \\
\hline Chacabuco & 10563 & 31 & 10 & 176 \\
\hline Escuelas ambulantes & & & 8 & 134 \\
\hline Total & 116366 & 283 & & 15 \\
\hline
\end{tabular}

* Correspondiente al censo 1914 desagregado por departamento.

** Extraído de Gez (1997: 341)

*** Producción propia del dato a partir del catálogo y documentación existente sobre la ENF en el INAPL y su cruce con los datos disponibles en Gez (1997).

Cuadro 1. Distribución de las escuelas Láinez existentes y participantes en la ENF por departamento

Los datos presentados en el cuadro dan cuenta de una estructura institucional de gran alcance y despliegue para poder plantear la factibilidad de la ENF. A su vez, los maestros eran un factor clave en este entramado ya que estaban atravesados por un proceso de profesionalización de la tarea educativa. El sistema escolar consolidado durante estos años se sostuvo bajo un proyecto "normalizador" que tendía a la formación de maestros y maestras por medio de las escuelas normales para así erradicar a la figura del "maestro espontáneo". Los números son elocuentes en este sentido: para 1920, de los 4022 maestros de las escuelas nacionales primarias de la ley Laínez casi el 82\% en promedio contaba con título docente. En San Luis, los números ascienden ya que de los 397 maestros nacionales existentes, 381 estaban titulados (96\%) (Schoo, 2012).
15. Si bien esto da cuenta de una clara tendencia centralizadora en la cual la educación debía ponerse al servicio de la organización del Estado liderado por un modelo oligárquico conservador, (Lazzari y Dono Rubio, 2007), entendemos que el proceso de nacionalización y centralización nunca sucede de modo unidireccional sino a partir de una relación entre centro e interior. En el caso de San Luis, Juan W. Gez -uno de los principales intelectuales locales de la época- sin desconocer el mandato constitucional que obligaba a las provincias a impartir educación, defendía la intervención nacional en esta materia: "las escuelas nacionales han de seguir predominando por la exigüidad de las rentas de algunas provincias, como la nuestra, y por las mayores garantías que ofrece a los maestros el Consejo Nacional de Educación" (Gez, 1997 [1937]: 340).

16. Con respecto al alcance nacional de la encuesta, cabe mencionar que la provincia de Santiago del Estero cuenta con la mayor cantidad de legajos (435), mientras que los Territorios Nacionales descienden claramente en número; por ejemplo, La Pampa tiene 86 y Río Negro 20. El material de San Luis tiene la particularidad de que uno de sus maestros (Luis Jerónimo Lucero, Leg. 77, escuela Ambulante E) obtuvo el primer premio nacional otorgado por el Consejo Nacional de Educación por la cantidad y calidad del material recolectado, el cual consta de 515 páginas. Ver Fernández Latour de Botas (1981) y Pérez Gutiérrez de Sánchez Vacca (2002). 
17. Para 1920 en la ciudad de San Luis existían dos escuelas normales de maestros -una de varones y otra de mujeres- y otras dos escuelas de maestros mixtas ubicadas en Villa Mercedes y San Francisco del Monte de Otro (Memoria del Ministerio de Justicia e Instrucción Pública 1921: s/pág.)

18. Este rol se observa en una nota publicada por la revista Monitor de la Educación Común del Inspector Nacional de Escuelas de la provincia de San Luis, Abraham J. Jofré, dirigida al Inspector General de Provincias, Juan P. Ramos. Allí relata una iniciativa local exitosa de formación de sociedades de "Amigos de la Educación", en torno a cada escuela nacional, impulsadas por los visitadores con el objeto de "vincular estrechamente el hogar y la escuela" (Monitor de la educación común 1917: 14).

19. De los 176 docentes participantes, 112 eran maestras $(64 \%)$ y 64 maestros (36\%).

20. A partir de gestiones realizadas por su decano Ricardo Rojas, el CNE donó a la Facultad de Filosofía y Letras de la Universidad de Buenos Aires el material documental recopilado por la Encuesta. Se creó entonces el Instituto de Literatura Argentina dirigido por Rojas y, en ese marco, se realizó este catálogo (Espósito y Di Croce, 2013). Esta donación se fundamentó sosteniendo que de este modo la $\mathrm{Fa}$ cultad podría indicar "cuáles eran las más valiosas contribuciones individuales, a fin de que el Consejo pudiese otorgar a los maestros contribuyentes los premios que les había prometido como estímulo, al iniciar la encuesta" (Rojas, 1925: VII). El material se organizó por provincia y se ordenaron alfabéticamente los legajos individuales de acuerdo al nombre del maestro correspondiente. Según la exposición de Rojas, el catálogo era meramente "descriptivo" ya que el material era tan amplio y diverso que, en esa instancia inicial, no podría haber sido ordenado de un modo más sistemático y científico (por ejemplo, por temas).
Por consiguiente, la gran mayoría de los maestros de San Luis encargados de realizar las recopilaciones tenían título docente $\mathrm{y}$, muy probablemente, se hayan formado en alguna de las cuatro escuelas normales nacionales existentes en la provincia. ${ }^{17}$ Esto da cuenta de que el contexto de producción del acervo documental que significa la ENF estaba signado por un marco estatal-nacional que se sostenía mediante instituciones centralizadas y agentes descentralizados, como eran, los inspectores y visitadores de escuelas. ${ }^{18}$ Cada provincia contaba con un referente encargado de ser el nexo entre las resoluciones e indicaciones del CNE y los directores y maestros de las escuelas nacionales repartidas en todo el territorio nacional.

En este sentido, esta estructura político-institucional ligada a un contexto intelectual particular constituía una de las múltiples mediaciones a considerar a la hora de analizar los legajos. En este marco, los maestros eran una suerte de agentes intermedios insertos en este entramado que implicaba profesionalización y formalización de la tarea docente, pero también capacidad y margen de resignificación y selección a la hora de transcribir las narraciones.

\section{Trazando un mapeo de los legajos con referencias indígenas}

Los papeles enviados por los maestros en el marco de la ENF se encuentran actualmente en el INAPL, están microfilmados y ordenados en un formulario/ legajo identificado en su carátula con el nombre del maestro y el número y lugar de la escuela correspondiente. Este conjunto de formularios conforma la colección de cada provincia. En el caso de San Luis, como participaron 176 maestros, encontramos ese mismo número de legajos. ${ }^{19}$ A su vez, contamos con un catálogo realizado en 1925 que indica, por provincia, los nombres de los maestros participantes, la escuela que les corresponde y una enumeración de los ítems contenidos en cada formulario. ${ }^{20}$ Aunque la información coincide en su amplia mayoría entre el catálogo y los legajos, en algunos casos encontramos que el maestro no indicó en su redacción a qué ítem clasificatorio correspondía la información incluida pero el catálogo sí la distingue bajo un subtítulo específico.

A modo de ejemplo, a continuación transcribimos la información contenida en el catálogo de San Luis correspondiente a un legajo:

\begin{tabular}{|c|c|}
\hline \multicolumn{2}{|r|}{ N.ำ 9 - Ameglio, Clemencia P. R. de (Anchorena, Escuela 74) } \\
\hline \multicolumn{2}{|r|}{ PRIMER ENVÍO } \\
\hline \multicolumn{2}{|c|}{ Poesías y Cantares: } \\
\hline & Cuentos: Balada (cinco coplas) \\
\hline & $\begin{array}{l}\text { Danzas: Marote (una copla); Correntino (una copla); Huellas (una copla); Palito } \\
\text { (tres coplas); Firmeza (una copla); Mariquita (dos coplas); Gato (cuatro coplas); } \\
\text { Resbalosa (una copla) }\end{array}$ \\
\hline \multicolumn{2}{|c|}{ Conocimientos populares: } \\
\hline & Etnografía: Vocabulario de los indios araucanos \\
\hline \multicolumn{2}{|c|}{ Supersticiones relativas a: } \\
\hline & Curanderismo y medicina: (diez) \\
\hline \multicolumn{2}{|c|}{ Narraciones, refranes, varios: } \\
\hline & Adivinanzas: El choclo; la lengua; el pelo; la aguja; el molino; ají. \\
\hline \multicolumn{2}{|r|}{ SEGUNDO ENVÍO } \\
\hline \multicolumn{2}{|c|}{ Conocimientos populares: } \\
\hline & $\begin{array}{l}\text { Etnografía: Costumbres indígenas; Léxico indígenas; Danzas indígenas } \\
\text { (descripción) }\end{array}$ \\
\hline
\end{tabular}

Tabla 1. Escuela Anchorena 
Al detenernos en el análisis de los legajos individualmente identificamos que hay 75 referencias explícitamente reconocidas como indígenas por parte del maestro que transcribe, contenidas en 38 legajos distintos. En la gran mayoría de los casos, se señala con nombre y apellido a los narradores, quienes en promedio se ubicaban entre los 60 y 80 años. En algunos legajos, se agrega alguna referencia adicional sobre el narrador como: "fue cautiva de los indios", "ha actuado con los indios en tiempo de invasiones a este pueblo", "vivió en compañía de los ranqueles siendo joven", "es una historia conocida por las personas más antiguas de este pueblo"; "descendientes de cautivas" o "conoció a los protagonistas de la historia". Cuando el maestro incluye la aclaración, el cautivo/a es la figura principal a partir de la cual se encuadran las referencias indígenas, salvo un único caso donde se refiere a la persona que relata como "indio".

A modo descriptivo, hemos agrupado las referencias indígenas en función a características similares:

1) Las más frecuentes presentan una narración histórica que involucra a una cautiva (o cautivo) y/o una situación en torno a las llamadas "invasiones de indios". Algunas de estas están precisamente datadas y remiten a algún acontecimiento presente en la historiografía como, por ejemplo, la invasión del caudillo Puebla junto a un grupo de ranqueles a la ciudad de Villa Mercedes en $1863{ }^{21}$ en otros casos, se hace mención a malones protagonizados por ciertos caciques o parcialidades lideradas por ellos -Mariano Rosas, Baigorrita, indio Blanco, cacique Peñaloza y Quechusdeo- y los efectos negativos que tenían en las poblaciones criollas. Principalmente, las narraciones remiten a los sufrimientos vividos por las mujeres y los niños tomados cautivos por los indios y las estrategias que se daban para afrontar estas situaciones.

2) En menor cantidad, pero igualmente importante, encontramos un conjunto de narraciones que describen una costumbre practicada por los indígenas. Entre ellas se incluyen rituales frente a casamientos, nacimientos y muertes. Por ejemplo, varios relatos dan cuenta de una práctica usual que implicaba que cuando un indio moría, era enterrado junto a sus alhajas, prendas y su caballo. También se realizaban ciertas celebraciones que duraban varios días e incluían bailes acompasados por "cajas de cueros" y mucha bebida y comida. Entre la vestimenta se destaca el uso de plumas, cueros, pulseras y pasadores de plata, botas de potro, vinchas, etc. Además, encontramos una descripción de las acciones que tomaban frente a los "gualichos"; es decir, cuando se propagaba una enfermedad contagiosa en las tolderías como la viruela. Frente a ello, levantaban el asentamiento y se dispersaban en el campo para evitar la propagación.

A modo de ejemplo, retomamos el relato de una costumbre transcripta por la maestra de la escuela 131. Tiene la particularidad de que el informante es Carlos Yanquetruz (60 años), quien porta un apellido ranquelino y la propia maestra lo califica como "indio":

\section{Nacimientos}

Entre estos indios los nacimientos se hacían de la siguiente manera: cuando [nacía] un niño la mujer que servía de partera le daba un nombre cualquiera; el indio y la india que tuviera el mismo nombre era como en nosotros la madrina y la encargada por tanto de hacerle regalos al recién nacido. A los diez años recién celebraban el nacimiento del niño el cual consistía en hacer un parlamento, o sea un banquete y completa borrachera. ${ }^{22}$
21. INAPL, ENF de San Luis, Legs. $10,55,74,158$ y 172.
22. INAPL, ENF de San Luis, Leg. 97, f. 7 . 
23. INAPL, ENF de San Luis, Leg. 9, f. 2.
3) En tercer lugar en orden de recurrencia, encontramos referencias a palabras, frases o relaciones indígenas con su traducción. En algunos casos, el maestro explicita que son "palabras araucanas" o "dialectos de los indios ranquelinos", en otros no se identifican pero vemos claramente que las transcripciones refieren a la lengua ranquelina:

\section{Palabras indígenas}

Uno: quiñé; dos: epu; tres: clá; cuatro: melí; cinco: quechú; seis: callú; siete: reglé; ocho: purá; nueve: allá; diez: marí.

Inché: yo soy

Aymí: ¿Cómo está usted? ${ }^{23}$

4) En menor medida encontramos menciones sobre el hallazgo de huesos y algunos objetos -como boleadoras- que se identifican como indígenas, la descripción de algunos nombres de lugares en las cercanías de la localidad de Anchorena que remiten a los indígenas de la zona y la transcripción de dos canciones sobre indios.

En el siguiente mapa observamos la distribución geográfica de las narraciones en función a la clasificación expuesta. El tamaño de la llamada marcada en el mapa es proporcional a la cantidad de referencias indígenas de esa categoría encontradas en ese sitio.

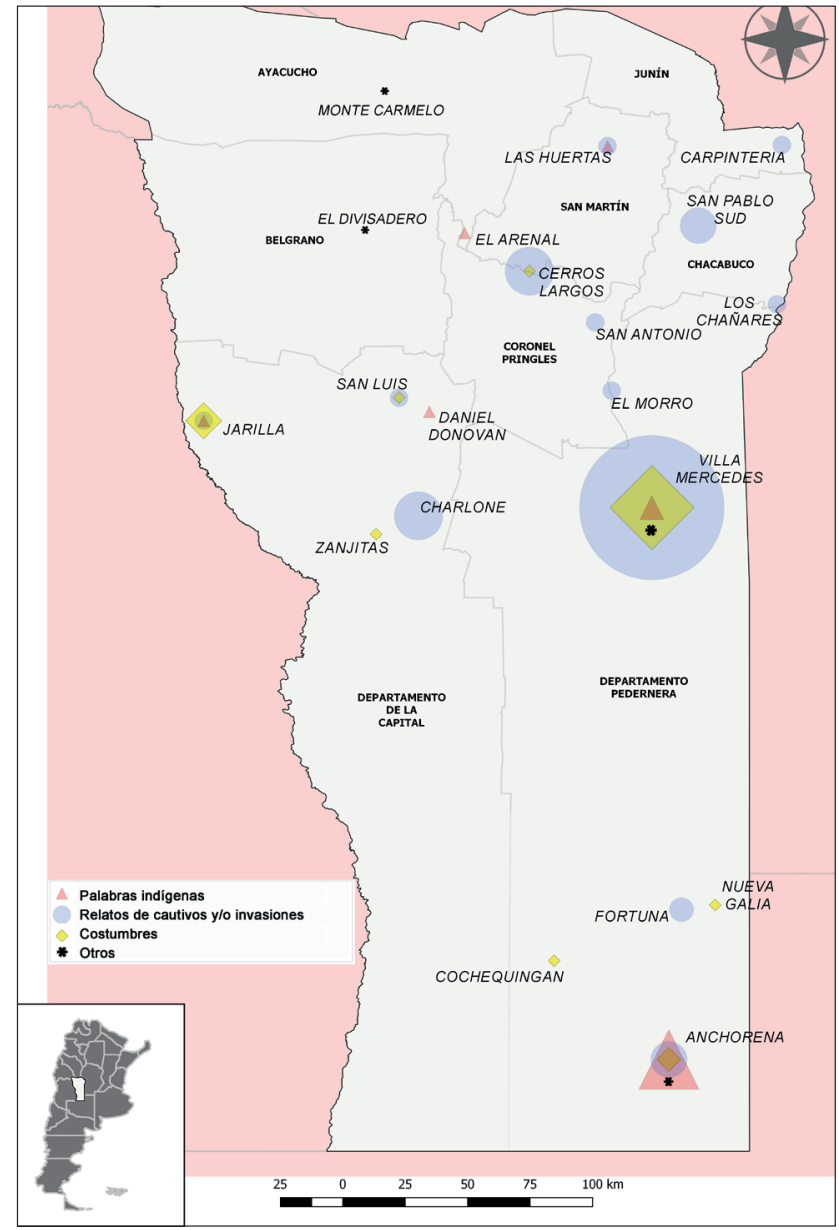

Mapa 1. Distribución geográfica de las narraciones que contienen referencias indígenas. Elaboración propia. 
Si consideramos la distribución de las narraciones en función a los departamentos, encontramos que el 56\% del total se ubica en Pedernera. Aunque no son menores las menciones en La Capital, Chacabuco y Pringles. Si bien en estos tres departamentos hay una preponderancia de relatos referidos a cautivos e invasiones -lo cual nos lleva a inferir los lugares a los que llegaron los malones más allá de la frontera ubicada en el río Quinto-, también encontramos diversidad de narraciones, como el caso de la escuela ubicada en Jarilla. Allí se ubica el legajo que contiene los relatos de Carlos Yanquetruz, resultando uno de los más extensos y ricos en torno la temática que nos convoca.

\begin{tabular}{|c|c|c|c|c|c|c|c|c|c|c|}
\hline \multirow{3}{*}{ Departamento } & \multicolumn{10}{|c|}{ Referencias indígenas } \\
\hline & \multirow{2}{*}{ Total } & \multirow{2}{*}{$\%$} & \multicolumn{2}{|c|}{$\begin{array}{l}\text { Cautivos y/o } \\
\text { invasiones }\end{array}$} & \multicolumn{2}{|c|}{ Costumbres } & \multicolumn{2}{|c|}{$\begin{array}{l}\text { Palabras } \\
\text { indígenas }\end{array}$} & \multicolumn{2}{|c|}{ Otros } \\
\hline & & & Total & $\%$ & Total & $\%$ & Total & $\%$ & Total & $\%$ \\
\hline Pedernera & 42 & $56 \%$ & 18 & $51 \%$ & 11 & $65 \%$ & 7 & $58 \%$ & 6 & $55 \%$ \\
\hline La Capital & 13 & $17 \%$ & 6 & $17 \%$ & 5 & $29 \%$ & 1 & $8 \%$ & 1 & $9 \%$ \\
\hline Chacabuco & 5 & $7 \%$ & 4 & $11 \%$ & - & - & 1 & $8 \%$ & & - \\
\hline Pringles & 7 & $9 \%$ & 5 & $14 \%$ & 1 & $6 \%$ & 1 & $8 \%$ & & - \\
\hline Junín & 1 & $1 \%$ & 1 & $3 \%$ & - & - & - & - & & - \\
\hline San Martín & 2 & $3 \%$ & 1 & $3 \%$ & - & - & 1 & $8 \%$ & & - \\
\hline Ayacucho & 1 & $1 \%$ & - & - & - & - & - & - & 1 & $9 \%$ \\
\hline Belgrano & 1 & $1 \%$ & - & - & - & - & - & - & 1 & $9 \%$ \\
\hline Escuelas ambulantes & 3 & $4 \%$ & - & - & - & - & 1 & $8 \%$ & 2 & $18 \%$ \\
\hline Total & 75 & $100 \%$ & 35 & $100 \%$ & 17 & $100 \%$ & 12 & $100 \%$ & 11 & $100 \%$ \\
\hline
\end{tabular}

Cuadro 2. Distribución porcentual de las referencias indígenas por departamento ycategoría.

Al detenernos en el Departamento Pedernera, cabe realizar algunas salvedades. Por un lado, podemos ver que Villa Mercedes -y sus alrededores- constituyen un punto importante en cuanto a cantidad y variedad de referencias indígenas. Esta localidad formaba parte del partido más poblado a nivel provincial, allí se incluían los legajos de seis escuelas distintas; mientras que en otros pueblos o parajes sólo existía una institución y un maestro para llevar-adelante la tarea de recopilación. Sin embargo, si hacemos una relación entre la cantidad de relatos y el número de población del partido correspondiente a cada región, la preponderancia de Mercedes se relativiza y se jerarquizan otras zonas, como el sur del Departamento Pedernera donde se ubican Anchorena, Cochequingan, Fortuna y Nueva Galia -correspondientes a los partidos Fortuna y Pueyrredón. ${ }^{24}$

\begin{tabular}{|l|c|c|c|c|c|}
\hline \multirow{3}{*}{ Partido } & \multicolumn{5}{|c|}{ Referencias indígenas en el Departamento Pedernera } \\
\cline { 2 - 6 } & $\begin{array}{c}\text { Palabras } \\
\text { indígenas }\end{array}$ & $\begin{array}{c}\text { Cautivos y/o } \\
\text { invasiones }\end{array}$ & Costumbres & Otros & Total \\
\hline Mercedes & 2 & 12 & 7 & 4 & 25 \\
\hline Pueyrredón & 5 & 3 & 3 & 2 & 13 \\
\hline Fortuna & - & 2 & 1 & - & 3 \\
\hline Morro & - & 1 & - & - & 1 \\
\hline Total & 7 & 18 & 11 & 6 & 42 \\
\hline
\end{tabular}

Cuadro 3. Distribución de las referencias indígenas por partido y tipo en el Departamento Pedernera.

Así como en el norte provincial, en Mercedes se observa una predominancia de registros que remiten a situaciones de invasiones y/o cautiverio con los
24. El Departamento Pedernera estaba conformado los partidos de Punilla, el Morro, Mercedes, Buena Esperanza, Fortuna y Pueyrredón, ubicados de norte a sur. En términos estadísticos en el partido de Mercedes hay un relato que contiene referencias indígenas por cada 911 habitantes, mientras que en los partidos Fortuna y Pueyrredón encontramos uno por cada 397 pobladores. 
25. En ese sentido, hemos identificado en trabajos anteriores la fundación del fuerte Constitucional en 1855 -luego denominado Villa Mercedes- como la medida adoptada a nivel provincial que tuvo mayores impactos en la modulación del espacio fronterizo y las relaciones interétnicas durante la segunda mitad de siglo XIX (Vacca, 2016).

26. Para la ubicación de esta rastrillada ver Mapa de Mansilla en la cartografía actual, blog de Norberto Mollo. Disponible en Internet: http://1.bp.blogspot. com/-DeHjcoen3O8/UcpjlFXJuol/ AAAAAAAABjk/w8hmtvbXZHM/ s16oo/Mapa+de+Mansilla+en+la+ cartograf\% $\mathrm{C}_{3} \% \mathrm{ADa}$ +actual.jpg

27. INAPL, ENF Leg.67, f.2. En este caso, la directora y maestra María S. G. de Grillo de la Escuela Nacional 106 de Nueva Galia se convierte en narradora e informante y describe las condiciones de vida de la "india Matilde" de 100 años de edad, que residía en ese momento al interior de una estancia bajo la protección del estanciero -quien permitía que viviera en su pequeño ranchito armado de "chapas y trozos de caldén" y le entregaba alimentos diariamente. indígenas. Al respecto, es fundamental considerar la importancia que tuvo este lugar en el desarrollo de las relaciones interétnicas durante el siglo XIX. La presencia de destacamentos militares, reducciones misioneras, incipientes poblaciones -con actividades productivas vinculadas al pastoreo- y grupos ranqueles que se acercaban a la frontera para realizar intercambios, recibir raciones a partir de los tratados o para realizar sus malones, eran característicos de un complejo y dinámico espacio fronterizo. ${ }^{25}$ Cuarenta años después de terminadas las campañas militares de 1878 y 1879, que derivaron en la desarticulación de este espacio, distintas personas relataban a los maestros -en el marco de esta encuesta- costumbres entre los ranqueles y experiencias vividas o escuchadas sobre las "invasiones" o situaciones de cautiverio.

En cambio, en la parte sur del Departamento Pedernera -que incluye a Anchorena, Nueva Galia, Fortuna y Cochequingan-, la distribución entre los distintos tipos de registros se vuelve más pareja. Creemos importante considerar que, a diferencia de Villa Mercedes que era espacio de frontera, estos sitios fueron espacios de radicación y circulación de los ranqueles. Además, se encuentran muy próximos a donde estaban ubicadas las tolderías de los caciques principales en Leuvucó y Poitague -actualmente parte de la provincia de La Pampa-, lugares que se conectaban con el espacio fronterizo por medio de la rastrillada de las pulgas. ${ }^{26}$ Una vez extendida la frontera nacional y provincial, se fundaron estos pueblos en San Luis como parte de una estrategia de "colonización" y población del "desierto". Los habitantes de estos sitios eran estancieros -en muchos casos ligados a la oligarquía argentina- que accedieron a la tierra a partir de su cercamiento y privatización; también había pequeños grupos rurales criollos e indígenas que sobrevivieron a las campañas militares diseminados en pequeños asentamientos que les permitían cierta reproducción autónoma y/o la incorporación al mercado de trabajo, en tanto peones de estancia. Esto podría explicar la mayor presencia de otro tipo de registros, además de los referidos a invasiones y/o cautiverio.

En resumen, el mapeo de los legajos nos permiten iluminar los siguientes aspectos: la ubicación geográfica de los lugares en donde se manifestaban costumbres indígenas y/o conocimiento de la lengua ranquel tras la "conquista del desierto"; la existencia de actores identificados como "indios", como es el caso de Carlos Yanquetruz ya mencionado, o la "india Matilde" cuyo modo de vida es narrado por la maestra, ${ }^{27}$ la identificación de eventos históricos que involucran a los ranqueles y han permanecido en la memoria popular repitiéndose en los relatos -principalmente la muerte del caudillo Puebla en un malón con participación ranquel a manos de un habitante de Villa Mercedes, Santiago Betbeder, y, en menor medida, la narración del combate de la Laguna Amarilla donde los informantes identificaron la participación de Juan Saá contra las fuerzas indígenas lideradas por Quechusdeo y acompañadas por Manuel Baigorria, quien se encontraba refugiado en sus tolderías bajo la protección del cacique; información sobre ciertos caciques del siglo XIX que aportan referencias sobre lugares de asentamiento, participaciones en malones y otros eventos como: 1) malones liderados por Mariano Rosas y Baigorrita dirigidos al espacio fronterizo y al norte provincial; 2 ) la existencia de distintas formas de intercambio comercial, como el ganado obtenido en los malones que luego era vendido en la frontera y la venta de una cautiva tomada de El Morro al cacique Calfucurá, descripta en un relato; 3) información sobre el indio Blanco, particularmente el señalamiento de que sus tolderías se ubicaban al sudoeste de Buena Esperanza y era un capitanejo de Mariano Rosas y el relato del suceso de su muerte en el marco de un malón dirigido hacia Córdoba; 4) el lugar de las tolderías del cacique Peñaloza, a cuatro leguas al sur de Fortuna 
en la laguna Ranquelcó; y 5) la presencia de pehuenches en la región, siendo Quechusdeo, Quinchaguala, Antigeu y Pedro Yanquetruz los caciques principales mencionados en el relato.

En la medida en que avancemos y profundicemos en la inscripción de estos discursos en una problemática más amplia que se interrogue por la circulación de memorias, prácticas y adscripciones ranqueles en la provincia, estos se convertirán en "fuentes" que aporten a configurar un archivo indígena local ${ }^{28}$ y a tensionar los discursos de desaparición que excluyeron a los indígenas de las narrativas provinciales dominantes. ${ }^{29}$

\section{Conclusiones}

Luego del recorrido realizado podemos comprender con mayor integralidad la reflexión de la maestra que citamos al principio de la introducción: allí están contenidas varias de las tensiones que reflejan el análisis del material documental realizado. Una provincia "sin indios" reconoce la presencia de sus saberes, prácticas y tradiciones, aparentemente congelados en el pasado en tanto objetos de recopilación folklórica. Sin embargo, la maestra Teresa C. de Pérez ilumina la contradicción y nos muestra que las palabras indígenas forman parte de una práctica viva y presente en el habla de los niños que la escuela busca conjurar.

Ahora bien, esta escuela formaba parte de un sistema educativo nacional que precisamente fue el soporte institucional ineludible para la realización de la ENF. Su estructura estatal, que conjugaba instituciones centralizadas y agentes descentralizados, operó como correa de transmisión entre el proyecto diseñado por ciertas elites culturales vinculadas al CNE y el maestro/etnógrafo encargado de producir la información a partir del diálogo. En este trabajo hemos descripto este escenario en profundidad porque entendemos que todos estos elementos constituyen mediaciones insalvables a la hora de adentrarnos en el análisis de lo dicho y lo no dicho en los documentos. Además de la contextualización, es fundamental el cruce con otras fuentes para complejizar los múltiples sentidos que circulan en las transcripciones de los maestros.

En este caso en particular nos hemos centrado en trazar un mapeo de las referencias indígenas presentes en los documentos lo cual nos ha permitido mostrar la circulación de distintas memorias, prácticas y saberes indígenas, luego de perpetrado el genocidio en 1878-1879, en un marco provincial signado por una matriz identitaria que obturó la posibilidad de incluir a los indígenas locales como uno de sus componentes. Esto constituye un primer paso que nos permitirá, en trabajos futuros, realizar un análisis cualitativo de los documentos y establecer comparaciones entre el material de la encuesta que involucra a un mismo pueblo indígena pero ubicado en distintas provincias, como sería, por ejemplo, el caso de los ranqueles.

Mediante el análisis realizado observamos que a diferencia del caso estudiado por Chamosa en el Valle Calchaquí, donde el material folklórico refleja un proceso de transición de la figura del indígena hacia el criollo, en el caso de San Luis este proceso parecería haber alcanzado su resultado final. Es decir, genocidio mediante, el problema del indio a nivel provincial aparecía como resuelto para el momento de la ENF, por lo que la uniformización y homogeneización cultural se presentaba más como una realidad consumada que como un proyecto a construir. Por consiguiente, la inclusión de referencias indígenas explícitas
28. Al respecto, Escolar propone la relectura de un corpus documental diverso -oral y escrito- susceptible de ser transformado en "fuentes huarpes" en la medida en que son contextualizados "desde una teleología huarpe, donde una institucionalidad o el desarrollo de una historia pensada como nacional no es el marco subyacente" (2014: 6).

29. En esa línea, podemos ver cómo el acervo existente en la encuesta relevado en el que en ese momento era Territorio Nacional de La Pampa ha servido para nutrir y fortalecer prácticas de recuperación y revalorización cultural de los ranqueles en la actualidad. Esto lo podemos ver en el manual de lengua ranquel editado en 2013 por parte de referentes de las comunidades y académicos universitarios en donde se cita la práctica del ngillatun recopilada por un maestro en la Colonia Pastoril Emilio Mitre narrada por el Cacique Santos Morales (Cabral et al., 2013: 103). 
estaba habilitada en tanto resabios puntualmente localizados que expresaban prácticas y discursos del pasado y no parecían amenazar la representación de la cultura local criolla incorporada al cuerpo homogéneo de la nación.

Aunque aquí hemos priorizado un análisis más general de los documentos, en pos de seguir comprendiendo la diversidad local, resulta necesario profundizar en otras estrategias de lectura oblicua del material que permitan "leer a contrapelo" ciertos relatos no explícitamente identificados como indígenas, pero en torno a los cuales pueda plantearse una vinculación a la temática. Por ejemplo, un análisis similar al que hemos realizado aquí se podría encarar en torno a las narraciones de caudillos identificados como gauchos en los documentos de la ENF (Chapanay y Santos Guayama) ${ }^{30}$ pero que, en función a ciertas investigaciones existentes, podemos vincular a la historia huarpe de cuyo (Escolar, 2007 y 2014).

Por todo lo expuesto, creemos que este material documental aporta a la complejización de matrices identitarias nacionales y provinciales que tantas veces se alejaron del reconocimiento de la pluralidad y diversidad a partir de la creación de fronteras de inclusión/exclusión de los otros internos de la nación (Briones, 2008). Asimismo, toda la estructura institucional que vehiculizó la ENF nos permite visualizar una forma particular -provincial-nacional- de presencia y expansión estatal en el territorio. En este contexto, aparecen las referencias indígenas como trazos de emergencia que, mediante una relectura, buscamos inscribir en un archivo que dé cuenta de las memorias silenciadas y de la profusa diversidad local.

\section{Agradecimientos}

Este trabajo fue presentado de modo preliminar en el simposio "Historia indígena y archivos: diversidad, relecturas y experiencias metodológicas" coordinado por Lorena Rodríguez y Xochitl Inostroza Ponce en el marco del II Congreso internacional "Los Pueblos indígenas de América Latina". Agradezco a ambas por el espacio y a los compañeros y colegas por sus comentarios. Además, a Lía Quarleri, Bettina Sidy, Bárbara Aguer, Muriel Morgan, Magalí Torres y a los evaluadores anónimos por sus valiosas sugerencias. También, a Cristian Poczynok por su ayuda en la elaboración del mapa, y a Susana Pérez Gutiérrez de Sánchez Vacca por compartir intereses y documentos conmigo. 


\section{Fuentes documentales citadas}

Instituto Nacional de Antropología y Pensamiento Latinoamericano (INAPL)

»Catálogo de la Colección de Folklore, Tercera serie, Tomo IV, N³, San Luis, 1937. Buenos Aires, Imprenta de la Universidad de Buenos Aires. Centro de Documentación Juan Alfonso Carrizo.

»Encuesta de Folklore, 1921. Legajos correspondientes a la provincia de San Luis (1-176). Centro de Documentación Juan Alfonso Carrizo.

Biblioteca Nacional de Maestros (BNM)

» Memoria del Ministerio de Justicia e Instrucción Pública, 1921.

» Monitor de la Educación Común, año 35, no. sección oficial, 1917. Disponible en internet: http://www.bnm.me.gov.ar/ebooks/reader/reader.php?mon=1\&vt=n\&dir $=00150859 \& \mathrm{c}$ $=0002 \&$ num_img=1\&num_fin=62. Consultado el 1 de enero de 2017.

» Monitor de la Educación Común, año 39, no. sección oficial, 1921a. Disponible en Internet: http://www.bnm.me.gov.ar/ebooks/reader/reader.php?mon=1\&vt=n\&dir=00150876\&c $=0002 \&$ num_img=1\&num_fin=62. Consultado el 1 de enero de 2017.

» Monitor de la Educación Común, año 39, no. 582, 1921b. Disponible en Internet: http:// www.bnm.me.gov.ar/ebooks/reader/reader.php?mon=1\&vt=n\&dir=00150876\&num_ img=176\&num_fin=188. Consultado el 1 de enero de 2017.

" “Mapa de Mansilla en la cartografía actual” en Mollo, N. [blog], La Etnohistoria de la Pampa. Disponible en Internet: www.norbertomollo.blogspot.com.ar Consultado el 26 de marzo de 2018.

\section{Archivo General de la Nación (AGN)}

» Mapa de la República Argentina confeccionado en el marco del Segundo Censo Nacional, 1895. Mapoteca. 


\section{Q Bibliografía}

"Arata, N. y M. L. Ayuso (2007). “Conflictos, tensiones y fracturas en la formación del sistema educativo argentino: Tres perspectivas sobre la Ley Láinez" en A cien años de la ley Láinez: 15-34. Buenos Aires, Ministerio de Educación, Ciencia y Tecnología. Disponible en internet: http://www.me.gov.ar/curriform/publica/cien_anios_ley_lainez. pdf. Consultado el 13 de junio de 2017.

» Blache, M. (1992). Folklore y nacionalismo en la Argentina: su vinculación de origen y su desvinculación actual. Runa XX: 69-89.

» Briones, C. (2008). “Formaciones de alteridad: contextos globales, procesos nacionales y provinciales” en Briones, C. (comp.), Cartografías Argentinas. Políticas indigenistas y formaciones provinciales de alteridad: 9-36. Buenos Aires, Antropofagia.

»Cabral, D., Serraino, N. y A. Díaz-Fernández (2013). Curso de Ranquel. Santa Rosa, Universidad Nacional de La Pampa.

" Chamosa, O. (2008). Indigenous or Criollo: The Myth of White Argentina in Tucumán's Calchaquí Valley. Hispanic American Historical Review 88 (1): 71-106.

" Chicote, G. (2013). De gauchos, criollos y folklores: los conceptos detrás de los términos. Anales de Literatura Hispanoamericana 42: 19-34.

»Darnton, R. (1987). La Gran Matanza de Gatos y otros episodios en la historia de la cultura francesa. México, Fondo de Cultura Económica.

»De Jong, I. (2005). Entre indios e inmigrantes: el pensamiento nacionalista y los precursores del folklore en la antropología argentina del cambio de siglo (XIX-XX). Revista de Indias LXV (234): 405-426.

»De la Fuente, A. (2007). Los hijos de Facundo. Caudillos y montoneras en la provincia de La Rioja durante el proceso de formación del Estado nacional argentino (1853-1870). Buenos Aires, Prometeo.

» Donoso Romo, A. (2009). La nación como protagonista de la educación en América Latina 1870-1930. Rhela 4: 239-266.

» Dubini, M. y B. Orovitz (2007). “La ley Láinez y la consolidación del centralismo” en A cien años de la ley Láinez: 57-72, Buenos Aires, Ministerio de Educación, Ciencia y Tecnología. Disponible en internet: http://www.me.gov.ar/curriform/publica/cien_anios_ley_lainez. pdf. Consultado el 13 de junio de 2017.

»Dupey, A. M. (1998). La siempre vigente Encuesta de Folklore del año 1921. Revista de la Escuela de Antropología 4: 9-16.

»Escolar, D. (2007). Los dones étnicos de la nación. Identidades huarpey modos de producción de soberanía en Argentina. Buenos Aires, Prometeo.

»Escolar, D. (2014). La naturaleza impura de las cosas folklóricas. Interdisciplina, teleología y elaboración de un archivo huarpe. Corpus. Archivos virtuales de la alteridad americana 4 (1): 1-12.

»Espósito, F. y E. V. Di Croce (2013). Un archivo del folklore nacional: La Encuesta de Magisterio de 1921. VI Jornadas de Filología y Lingüística, 7 al 9 de agosto de 2013, La Plata, Argentina. Memoria Académica. Disponible en internet:http://www.memoria. fahce.unlp.edu.ar/library? $a=d \& c=$ eventos\&d=Jev3849. Consultado el 5 de junio de 2017 . 
» Farberman, J. (2014). Debate: Historia, antropología y folclore. Presentación. Corpus. Archivos virtuales de la alteridad americana 4 (1): 1-4.

» Fernández Latour de Botas, O. (1981). Sesenta años después. Visión crítica actual de la Colección de Folklore de 1921. Revista Nacional de Cultura 10: 105-140.

» Gez, J. W. [1937] (1997). Geografía de la provincia de San Luis. Tomo III. San Luis, Payné.

»Lazzari, A. (2010). Autonomy in Apparitions: Phantom Indian, Selves, and Freedom. Tesis Doctoral inédita. Nueva York- NY, Department of Anthropology, Columbia University.

» Lazzari, M. yS. Dono Rubio (2007). “La ley Láinez en el debate federalismo - centralismo: un interregno entre las palabras y las cosas" en A cien años de la ley Láinez: 47-57. Buenos Aires, Ministerio de Educación, Ciencia y Tecnología. Disponible en internet: http://www.me.gov.ar/curriform/publica/cien_anios_ley_lainez.pdf. Consultado el 13 de junio de 2017.

»Lenton, D. (2011). Presentación del debate: Genocidio y política indigenista. Debates sobre la potencia explicativa de una categoría polémica. Corpus. Archivos virtuales de la alteridad americana: 1 (2): 1-3.

»Pérez Gutiérrez de Sánchez Vacca, S. (2002). Homenaje a los Maestros de San Luis que respondieron a la Encuesta de 1921. San Luis, Fondo Editorial Sanluiseño.

» Rojas, R. (1925). “Advertencia” en Catálogo de la Colección de Folklore: 5-9. Buenos Aires, Instituto de Literatura Argentina/ Imprenta de la Universidad de Buenos Aires.

»Salomón Tarquini, C. (2010). Largas noches en La Pampa. Itinerarios y resistencias de la población indígena (1878-1976). Buenos Aires, Prometeo.

»Schoo, S. (2012). “La organización de la educación secundaria, normal y especial en Argentina” en Ruiz, G. (comp.), La estructura académica argentina. Análisis desde la perspectiva del derecho a la educación: 91-138. Buenos Aires, Eudeba.

» Steiman, A. L. (2011). “Detrás de lo criollo. Tensiones clasificatorias sobre lo indígena en Amaicha del Valle. Primeras décadas del siglo XX” en Rodríguez, L. (comp.), Resistencias, conflictos y negociaciones. El Valle Calchaquí desde el período prehispánico hasta la actualidad: 145-169. Rosario, Prohistoria ediciones.

» Thompson, E. P. (1989) Folklore, antropología e historia social. Historia Social 3: 81-102.

»Vacca, L. C. (2014). “Intersecciones de género, raza y clase: Análisis crítico del relato mítico-histórico sobre Juana Koslay y la fundación de la ciudad de San Luis” en Catelli, L. y M. E. Lucero (eds.), Materialidades (pos)coloniales y de la (de)colonialidad latinoamericana: 83-99. Rosario, UNR Editora.

»Vacca, L. C. (2015). La provincia de San Luis y sus otros: Discursos y políticas oficiales implementadas frente a los ranqueles durante la segunda mitad de siglo XIX. Tesis de Maestría en Sociología de la Cultura y Análisis Cultural, Inédita. Buenos Aires, IDAES/ UNSAM.

»Vacca, L. C. (2016). Política institucional y relaciones interétnicas: Dinámicas del espacio fronterizo en la provincia de San Luis durante el proceso de formación del Estado nación argentino (1855-1870). Coordenadas. Revista de Historia Local y Regional 3 (2): 1-30. 